\title{
Creation of "necessary" mixtures of baking soda, hydrogen peroxide and warm water as a strategy for modernization bleaching cleaners of ceramic
}

\author{
ALEKSANDR URAKOV - Udmurt Federal Research Center of the Ural branch \\ of the Russian Academy of Sciences • urakoval@live.ru
}

Érkezett: 2019. 10. 13. - Received: 13. 10. 2019. - https://doi.org/10.14382/epitoanyag-jsbcm.2020.6

\begin{abstract}
Hydrogen peroxide solutions have been used for more than 100 years as industrial bleach for various wood, paper, textile, leather products, as well as for hair whitening. Since the same time, hydrogen peroxide solutions and sodium bicarbonate solutions have been widely used in medicine as antiseptic and disinfectants to remove pus from purulent wounds. Less than this period, hydrogen peroxide solutions are successfully used for bleaching fish and various seafood. However, until the early 21st century, the combination of hydrogen peroxide with sodium bicarbonate was not used as a bleaching cleaner for surfaces contaminated with blood and/or pus stains. The use of hydrogen peroxide solution in combination with sodium bicarbonate as a universal bleaching and dissolving medical cleaner was first proposed in the last 20 years in Russia. It was during these years that a new group of drugs was discovered in pharmacology: drugs, bleaching and dissolving blood stains and a mass of thick pus. It is proved that the local application of various mixtures of baking soda, hydrogen peroxide and warm water provides a safe urgent dissolution and discoloration of the dense biological masses. It is established that purification, bleaching and removal of organic pollutants is achieved due to their hyperthermal softening, cavitation loosening, alkaline saponification and dissolution, as well as due to oxidative discoloration of pigments. It is proposed to use the created Arsenal of biomedical alkaline bleaching cleaners for the analysis and development of new effective and safe ceramic bleaches in everyday life.

Keywords: teeth, dentures, ceramic, hydrogen peroxide, sodium hydrogen carbonate, bleaching agent

Kulcsszavak: fogak, fogsorok, kerámia, hidrogén-peroxid, nátrium-hidrogén-karbonát, fehérítô
\end{abstract}

\section{Introduction}

One of the distinguishing features of high-quality ceramic tableware and many other ceramic, bioceramic, clay and metal products intended for storage, preparation and consumption of food products is the presence of enamel on their working surface. This enamel in its physical and chemical properties is very similar to the enamel that covers the working surfaces of mollusk shells, human and animal teeth. Such enamel is also covered of modern ceramic and/or metal-ceramic dentures and braces [1]. The common property of all these enamels is that they have a very high strength and a very smooth and slippery surface that does not even have a micropore. Therefore, the surface of these enamels has low adhesion to organic substances and microorganisms and is easily cleaned from dirt when washing [2]. In turn, the purity of the enamel surface affects the contamination of products and determines the aesthetic properties of the product [3].

In addition, the cleanliness of the working surfaces of the discussed products is the main task of sanitary and hygienic control of their quality. The fact is that the remains of food products, stuck to the surface of the enamel, can turn into a kind of fertile bed for the reproduction of microorganisms, of which some part can become a breeding ground for infectious diseases. Therefore, in practice, the contamination of surfaces is investigated not so much for the presence of food products on it, as for their contamination with microorganisms $[4,5]$.

Therefore, it is no accident that wherever objects and products covered with enamel are used, hygienic means are constantly and repeatedly used to care for them, or rather-to clean the enamel surface from mechanical and microbiological contaminants. Therefore, at all times the production of ceramics and enamels has been inextricably linked with the production of disinfectants, detergents, bleaching and hygiene products [6].

In the second half of the 20th century, the world has increased interest in household ceramic products. In the late 20th century and early 21 st century, the demand for ceramic and bioceramic medical products increased. Nowadays, the demand for ceramic products used in dentistry is especially great [7].

Due to the high demand for ceramic products, their quantity, range and quality has increased significantly. At the same time, the use of known detergents and devices (washcloths, sponges, wipes, mops, brushes, Soaps, shampoos, washing powders, washing machines, food processors, etc.), personal 
hygiene products in the oral cavity (toothpastes, toothbrushes, toothpicks, elixirs, etc.) still does not allow you to quickly achieve whiteness and purity of the surfaces of enamels covering cookware, baths, sinks, ceramic tiles, as well as teeth and dental constructions $[1,8]$. Therefore, within a few days or weeks after the start of the use of ceramic products, their surface becomes dirty and remains dirty regardless of the quality of enamel and hygiene products. It impairs the appearance of household products (such as cups, dishes, pots, pans, knives), teeth, dentures, braces and causes bad breath in humans and animals [9]. All this encourages researchers to search for new more effective means of washing and whitening enamel covering ceramic products.

The analysis of known detergents and cleaning agents, devices and methods of their application was carried out. It is shown that most traditional technical solutions are based on the principle of mechanical cleaning of the enamel surface from food contamination [10]. However, the effectiveness and safety of known detergents and bleaching agents and methods of their application is still not completely satisfied with consumers. At the same time, progress in this direction has slowed. This is probably due to the fact that the potential of this principle is almost completely exhausted. That is why to optimize the search for new tools, it is proposed to pay attention to a different principle of washing and whitening enamels.

In particular, as a new principle of enamel cleaning, the principle of physical-chemical dissolution of adhesives is proposed, which bind together all the residues of organic substances into one dense biomass, visible to the eye and assessed as a stain of pollution. It is shown that this principle can be realized with the help of hydrogen peroxide solution, to which sodium bicarbonate and/or oxygen gas under excessive pressure are added in excess [11]. Such a solution provides urgent purification and bleaching of the enamel surface from biological pollutants due to alkaline saponification of protein and protein-lipid complexes, "explosive" loosening of biomass due to cold boiling caused by the release of gas (in particular, oxygen) inside this biomass, and oxidative destruction of lightabsorbing double bonds in pigments [12-14]. In this case, such a cleaner is safe for the consumer, as it includes edible ingredients [15].

It is demonstrated that this principle is successfully implemented in medicine for urgent dissolution of thick purulent masses, sulfur plugs and dried blood [11]. For this purpose, special technologies for the local application of alkaline aqueous solutions of hydrogen peroxide heated to 37 - $42{ }^{\circ} \mathrm{C}$, saturated with oxygen gas under increased pressure and sometimes supplemented with an insoluble material with frictional properties are proposed [16]. It is noted that these physical and chemical factors have long been considered very important in terms of physical and chemical sciences. However, further research into their use in the field of hygiene is needed in order to develop more effective and safe cleaning and bleaching agents suitable and safe for the treatment of ceramic products in the home.

At the same time, the influence of these and other physical and chemical factors on the removal of dirt from the surface of enamels of ceramic products is still insufficiently studied.

\section{Materials and methods}

Since 1999, the search for patents for inventions and scientific information on new means and methods of dissolution and removal of dense biological masses using physical and chemical factors of local interaction has been continuously conducted. The search strategy keywords were as follows: brushes, mops, brooms, washcloths, soaps, shampoos, laundry detergent, washing powder, bleach, cleaner, tooth cleaner, thick pus solvent, toothpaste, blood stain, pus, tattoo, plaque, tooth, denture, ceramic ware, textiles, ceramics, skin and bruise. Key words were limited to means and ways of using them for hygienic and aesthetic purposes.

The criteria for inclusion of a scientific source were limited to the availability of information about the invented drugs and/or methods of their application, which allow due to physical and chemical factors of local interaction to urgently dissolve, discolor and remove from the surface of the skin, textiles or enamel stains of dried or thick blood and / or pus. The criterion of exclusion from the article was the lack of information about the invented means and / or methods providing urgent dissolution, removal of blood stains and pus from the contaminated surface and its bleaching with a local single application. The risk of individual bias in judgments was reduced by relying on the essence of the invention as a generally accepted criterion of novelty. A total of 29750 sources of information were examined, of which only 25 inventions were evaluated for consideration.

\section{Results and discussion}

The results of the analysis of the available scientific and patent information have shown that today there is no known means and no ingredient included in the composition of known combined preparations, the use of which separately from each other would ensure the rapid dissolution and loosening of biological stains bonded by coagulated proteins of animal, vegetable or microbial origin [11]. At the same time, the combination of hydrogen peroxide solution with alkali represents a surprisingly very promising direction for the development of new detergents, cleaning and bleaching agents. It is shown that in the last 20 years a whole Arsenal of new medicines and technologies of personal hygiene was invented, which allow for 1-2 minutes to completely clean the surface, stained with blood and/or pus $[12,18]$. The new drugs are designed for urgent dissolution, loosening, removal and discoloration of thick biological masses such as thick pus, sulfur plug, lacrimal stone and dry blood crust [11]. Such means are intended mainly for the treatment of purulent diseases (such as peritonitis, pancreonecrosis, pleurisy, otitis), thrombosis of vascular catheters and veins, as well as for discoloration of the skin and nail plates in the area of bruises and hematomas. The analysis showed that these drugs are aqueous solutions, and their main ingredients are hydrogen peroxide and sodium bicarbonate in certain ratios and concentrations [16].

Today it is safe to say that the development of a new group of detergents and bleaching hygiene products began in Russia [11]. The first means were developed for dissolving and removing thick pus from purulent wounds. In particular, the 
beginning of the patent for the first invention of this group of hygiene products begins officially with 29.12.2000. It was on this day that the patent application for the invention "Method of treatment of long-term non-healing wounds" (RU Patent 2187287) was registered. In this invention, for urgent cleansing of the wound from purulent necrotic masses, it was first proposed to irrigate the wound heated to $37^{\circ} \mathrm{C}$ with a solution of $3 \%$ hydrogen peroxide, after which it was proposed to warm the wound surface to $42{ }^{\circ} \mathrm{C}$. Then, in 2005 , the invention "Method for treating pleural empyema cases" (RU Patent 2308894) was created. It was the second invention in which for urgent removal of pus from the pleural cavity it was recommended to introduce into the purulent mass a solution of an alkaline surfactant heated to $42^{\circ} \mathrm{C}$.

In 2006, patent applications were filed for inventions such as "Hyper-gassed and hyper-osmotic antiseptic mixture" (RU Patent 2331441) and "Method for peritoneal dialysis using gasified solution" (RU Patent 2336833). In these inventions as a solvent of thick pus, an aqueous solution of 2.7-3.3\% hydrogen peroxide, $0.9-10.0 \%$ sodium chloride and gaseous carbon dioxide was proposed at an excess pressure of 0.2 ATM at +8 ${ }^{\circ} \mathrm{C}$. The new drug had the ability to cold boil in the purulent mass, so it literally "blew up" a monolithic piece of thick pus.

In 2009 there was a publication about 3 inventions: "Softening agent for thick and viscous pus" (RU Patent 2360685), "Malchikov's method of removing bile calculus" (RU Patent 2367375) and "Methods of diagnostics and treatment of clotted hemothorax" by A. Y. Malchikov (RU Patent 2368333). They were proposed to dissolve thick pus, gallstones and blood clots with warm solutions of hydrogen peroxide and sodium bicarbonate.

These inventions created the basis for the modernization of developments in the future. And so it happened: in the following years, the first successes in the urgent washing of various surfaces from thick pus and blood stains due to physical and chemical dissolution and loosening of biological masses continued to improve. The list of new drugs has increased. Today we can assume that the results can be transferred to another field of activity. In particular, the experience of creating new cleaners for the field of medicine can be used to create new cleaners for enamel ceramic products used in the field of life. It is likely that the most useful may be the results achieved in our time in the development of a group of drugs, loosening blood crusts and dissolving and brightening blood stains.

The fact is that the most difficult to remove stains that occur on tooth enamel and ceramic dishes are formed due to coagulation, denaturation and/or drying of proteins and protein-lipid complexes [19]. Therefore, proteins play the role of a kind of biological glue that glues pigment particles into a conglomerate and firmly adheres it to the surface of the enamel. The sources of this natural "glue" are animal and vegetable products containing proteins and fats [4]. In addition to readymade proteins, fats and oils, similar products of microbial processing of starch, sugar, fiber and other substances also participate in the bonding of organic substances [19]. The fact is that food is not sterile. Is not sterile and the surface of the enamel. Moreover, very often foods are pre-seeded with fungi (yeast) for culinary purposes.
It is also very important that the remains of food products after they are glued to the enamel always acquire a darker color, which rarely depends on the original color of the food. On the contrary, the transformation of color in an ordinary stain of enamel contamination is likely to be similar to the transformation of color in the mass of food eaten in the process of their movement in the gastrointestinal tract: the food eaten may consist of white products such as white bread, white starch, milk, cottage cheese and sugar, but the feces formed from them, normally acquire a dark brown color. In this regard, it is likely that the dark color of feces, plaque and stains on ceramic products (such as dishes) is determined by the microbiological process of processing food residues and the formation of conventional organic pigments.

It is no secret that the main pigment that stains feces and plaque in a dark brown color is the pigment stercobilin, which is formed as a result of enzymatic and microbial destruction of blood proteins and/or bile [17].

It is shown that the color of blood depends mainly on the color of red blood cells, the color of which, in turn, depends on the color of hemoglobin. It is believed that under the action of enzymes and microorganisms, hemoglobin is converted successively into verdoglobin, biliverdin, and then into bilirubin. Bile also contains the pigment bilirubin. Bilirubin is converted under the action of microorganisms first into urobilinogen, and then into stercobilin. Stercobilin is the pigment that gives "digested" foods a characteristic brown color [20].

It should be noted that people have long learned to remove from household items dark stains of animal and vegetable origin (they usually stain textiles, wool, paper, wood and leather). More than 100 years ago, wood ash and water passed through such ash were used for this purpose [21]. Today, specially designed washing powders and bleaching solutions are used for these purposes [22]. It was found that most of these solutions are aqueous solutions of hydrogen peroxide with special physical and chemical properties [23,24].

However, hydrogen peroxide has been used for more than 100 years for industrial washing and bleaching of various products of plant and animal origin, namely-wood, paper, textile, leather products [25]. At the same time, the safety of hydrogen peroxide for consumers of products bleached with this bleach was shown.

The experience of industrial application of hydrogen peroxide has shown that hydrogen peroxide is highly reactive, strong oxidizer and bleaching agent. It is shown that an increase in the concentration of hydrogen peroxide, an increase in the local temperature, an increase in the alkalinity of solutions above $\mathrm{pH} 7.0$ and an increase in the duration of interaction enhances the bleaching effect of hydrogen peroxide. It was found that the bleaching effect of hydrogen peroxide increases the addition of compounds such as peroxosulfates, sodium peroxodisulfate, potassium peroxodisulfate, carbamine peroxide, ammonium peroxodisulfate, sodium carbonate, ammonia and silicate $[23,24]$.

In addition, almost as many years hydrogen peroxide solutions are used for hair whitening. 
In modern times, hydrogen peroxide is used to disinfect the water in which live fish swim [26], as well as to bleach seafood such as squid, octopus and cuttlefish [27]. It has been shown that fish remains safe for humans when ingested.

The fact that hydrogen peroxide is able to discolor various organic pigments, it became known to people also for a long time. In particular, in 1982, it was shown that the bleaching effect of hydrogen peroxide on hemoglobin is associated with hemolysis of erythrocytes and with the destruction of lightabsorbing double bonds within colored pigments [28].

However, in the medical field, the first invention, which is a warm alkaline solution of hydrogen peroxide designed to discolor clothing stained with blood stains, was published in 2009. It was " a Method of rapid removal of blood stains from clothing” (RU Patent 2371532) [29].

Then in 2010, an article was published about a clinical case in which a urea gel containing $15 \%$ hydrogen peroxide minimized the discoloration and discomfort associated with ecchymosis [30]. It was shown that skin pigmentation in the area of ecchymosis was reduced due to the application of hydrated gel containing 5 to $20 \%$ hydrogen peroxide or urea peroxide to the skin during occlusion with an adhesive bandage.

In subsequent years, about 10 more drugs and methods were invented for urgent discoloration of the bloody bandage, skin and nail plate in the area of the wound, bruise and hematoma with solutions of $0.01-3 \%$ hydrogen peroxide and $1.7-10 \%$ sodium bicarbonate at a temperature of $37-42{ }^{\circ} \mathrm{C}$ [18]. Thus, during this period, the following inventions were developed: "Persons infrared differential express-diagnostics of bruising and injury of soft tissues" (RU Patent 2577510), "Bruise bleacher” (RU Patent 2539380), "Bleaching agent" (RU Patent 2589682), "Agent for intradermal bruise whitening" (RU Patent 2573382), "Method of skin discoloration in the area of bruising” (RU Patent 2582215), "Method for skin discoloration in bruising area” (RU Patent 2586278), "Method of removing paint from skin" (RU Patent 2600504), "Method for emergency bleaching and blood crust removal from skin in place of squeezed out acne" (RU Patent 2631593), "Means for intravital skin whitening near blue eyes" (RU Patent 2639485), "Method for whitening of bruise under eye" (RU Patent 2639283), "Bleaching opener of dried blood for wrapping bandages adhered to a wound" (RU Patent 2653465), "Decolorant of blood" (RU Patent 2647371), "Method for whitening of sore under nail" (RU Patent 2631592), "Method for blue nail treatment" (RU Patent 2641386) and "Method of emergency bleaching of the skin hematoma under the eye" (RU Patent 2679334).

The materials of these inventions prove that warm alkaline solutions of $0.1-3.0 \%$ hydrogen peroxide at $\mathrm{pH} 8.5$ are unsurpassed leaders in bleaching fresh, dry and old blood.

Analysis of the composition of the invented bleach bruises and hematomas showed that the preparations of this new group of funds differ from all known detergents following properties [11]:

1. The main ingredients of bruise bleach are water, hydrogen peroxide and sodium bicarbonate.

2. Water, hydrogen peroxide and sodium bicarbonate are safe substances.
3. All bruise, hematoma and blood stain bleaches are alkaline oxidizers and have a $\mathrm{pH}$ of 8.5.

4. Bruising bleaches are applied locally at a temperature of $37-42^{\circ} \mathrm{C}$.

5. Water, hydrogen peroxide and sodium hydrocarbonate when absorption into the blood do not cause poisoning.

Independent studies show that solutions of hydrogen peroxide and sodium bicarbonate are fairly stable [31].

To date, it has been found that the mechanism of local action of alkaline bleaching oxidants is as follows:

- with local action, they have the ability of alkaline saponification of proteins and protein-lipid complexes,

- they have the ability to destroy biological masses from within due to the process of cold boiling

- they have the ability to destroy the light-absorbing double bonds inside the colored pigments.

It is known that hydrogen peroxide solutions as a bleaching drug are safe for people [32]. Therefore, a solution of $3 \%$ hydrogen peroxide is sold in pharmacies without a prescription as a local antiseptic, a solution of $5 \%$ hydrogen peroxide is used for hair whitening, a solution of $6.5 \%$ urea peroxide is used as an over-the-counter softener of earwax, and a solution of urea peroxide at a concentration of $5-20 \%$ is widely used in dentistry for teeth whitening $[33,34]$. In turn, sodium bicarbonate is an edible substance and is used in cooking under the name "baking soda".

It should be noted that following the discovery of thick pus solvents and bleach bruises and blood stains were invented tools that can completely remove plaque from the surface of the teeth and ceramic dental structures in a few tens of seconds after the start of local interaction. So, in 2017, a patent for the invention "Frictional toothpaste" (RU Patent 2626669) was issued. In this invention, for the urgent removal of dental plaque, a solution of $9.5-10 \%$ sodium bicarbonate and 0.5 $1.5 \%$ hydrogen peroxide was first proposed, which in a ratio of $5 / 1$ mass is poured into crystalline sodium bicarbonate at a temperature of $+25-+26^{\circ} \mathrm{C}$. As a result, a thick paste is formed, in which soft sodium bicarbonate crystals have abrasive, frictional, adhesive, erasing, absorption and adhesive activity against the rough and soft surface of the "tooth" dirt, but not against the smooth and hard surface of the tooth enamel and the smooth surface of the gum mucosa. On the other hand, the solution due to the dissolved part of sodium bicarbonate causes alkaline hydrolysis of proteins and saponification of fats, and due to hydrogen peroxide as a result of the catalase reaction releases oxygen gas, the bubbles of which cause the effect of cold boiling and destruction of biological masses.

Then in 2018, a patent was obtained for the first "Bleaching cleanser of dentures" (RU Patent 2659952). The invented bleaching agent is an aqueous solution of $3 \%$ hydrogen peroxide and $2-10 \%$ sodium bicarbonate, which contains oxygen gas under an excess pressure of 0.2 ATM at $+8^{\circ} \mathrm{C}$. Before use, this drug is heated to a temperature of $37-42^{\circ} \mathrm{C}$. It is shown that the developed drug in a few seconds after the beginning of local interaction with dirty teeth, dentures, ceramic utensils and surgical instruments completely and automatically 
cleans, deodorizes and whitens their surface. Purification and bleaching is achieved by hyper temperature softening, alkaline saponification, cavitation loosening, dissolution and oxidative discoloration of various biological masses.

Thus, heated to $42{ }^{\circ} \mathrm{C}$ and saturated with oxygen gas under excessive pressure, aqueous solutions of $0.01-3 \%$ hydrogen peroxide and $1.7-10 \%$ sodium bicarbonate are automatically converted into strong detergents and bleaching agents. Such means are capable at single application within one minute automatically to clear enamel from a dental plaque, the rests of food, traces of pus, blood stains and from pollution by other biological products. At the same time, these bleaching agents remain safe. What's more, they are edible! (Fig. 1)

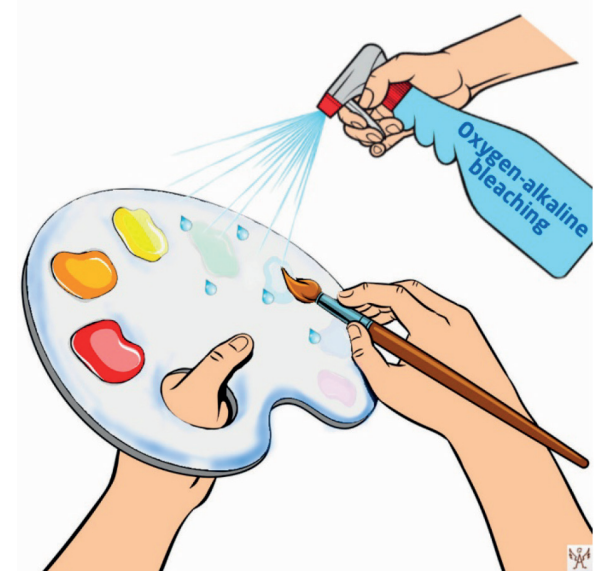

Fig. 1 Oxygen, used as a bleaching agent

1. ábra Oxigén, mint fehéritőszer

\section{Conclusions}

From the end of 2000 to the present time, more than 20 drugs and methods of their application in the medical field have been invented for emergency dissolution and discoloration of dense biological masses bonded by protein and protein-lipid complexes of blood and pus as a result of their coagulation and/or drying. Analysis of the composition of these preparations showed that all of them are aqueous solutions of $0.01-3 \%$ hydrogen peroxide and $1.7-10 \%$ sodium bicarbonate, heated to a temperature of $37-42^{\circ} \mathrm{C}$. It is shown, that the additional introduction of oxygen gas, carbon dioxide or other gases under excessive pressure, or insoluble sodium bicarbonate powder enhances and accelerates the washing and bleaching effect of these mixtures. It is established, that the mechanism of washing and bleaching action of such mixtures is that they have alkaline saponification of protein and protein-lipid complexes, the formation of gas bubbles at cold boiling and oxidative destruction of lightabsorbing double bonds inside the colored pigments. It is proposed to use the experience of development and the existing Arsenal of new medical alkaline bleaching cleaners blood stains and pus for the analysis and development of new effective and safe bleaching cleaners ceramics in the home.

\section{References}

[1] Madfa, A. A. - Yue, X-G.: Dental prostheses mimic the natural enamel behavior under functional loading: A review article. Jpn Dent Sci Rev. 2016 Feb; 52(1): 2-13. https:// doi.org./10.1016/j.jdsr.2015.07.001.
[2] Dorthé E. - Zhang Y.: Load-bearing increase in alumina evoked by introduction of a functional glass gradient. Journal of the European Ceramic Society. 2012; 32 (6): 1213-1220.

https://doi.org/10.1016/j.jeurceramsoc.2011.11.041.

[3] Fralick M. - Thomspson A. - Mourad O.: Lead toxicity from glazed ceramic cookware. CMAJ. 2016;188(17-18): E521-E524.

https://doi.org/10.1503/cmaj.160182.

[4] Alum E.A. - Urom S.M. - Otu C. - Ben C. M. A.: Microbiological contamination of food: The mechanisms, impacts and prevention. International Journal of Scientific \& Technology Research. 2016; 5 (03): 65-78. http://www.ijstr.org/final-print/mar2016/MicrobiologicalContamination-Of-Food-The-Mechanisms-Impacts-And-Prevention. pdf. [Last accessed on 2019 Nov 19].

[5] Tamburini E. - Donegà V. - Gabriella M.M. - Pedrini P. - Monticelli C. - Balbo A.: Study on microbial deposition and contamination onto six surfaces commonly used in chemical and microbiological laboratories. Int J Environ Res Public Health. 2015; 12(7): 8295-8311. https://doi.org/10.3390/ijerph120708295.

[6] Barker J. - Naeeni M. - Bloomfield S.F.: The effects of cleaning and disinfection in reducing Salmonella contamination in a laboratory model kitchen. J. Appl. Microbiol. 2003; 95 (6): 1351-1360. https://www.ncbi.nlm.nih.gov/pubmed/14633010.

[7] Shenoy A. - Shenoy N.: Dental ceramics: An update. J Conserv Dent. 2010 Oct-Dec; 13(4): 195-203. https://doi.org/10.4103/0972-0707.73379.

[8] Tumwebaze I.K. - Hans-Joachim Mosler H-J.: Shared toilet users' collective cleaning and determinant factors in Kampala slums, Uganda. BMC Public Health. 2014; 14: 1260. https://doi.org/10.1186/1471-2458-14-1260.

[9] Aylıkcı B.U. - Çolak H. Halitosis: From diagnosis to management. J Nat Sci Biol Med. 2013; 4(1): 14-23. https://doi.org/10.4103/0976-9668.107255.

[10] Naseem, S. - Fatima S.H. - Ghazanfar H. - Haq S. - Khan N.A. Mehmood M. - Ghazanfar A.: Oral hygiene practices and teeth cleaning techniques among medical students. Cureus. 2017; 9(7): e1487. 10.7759/ cureus. 1487

[11] Urakov A. - Urakova N. - Reshetnikov A.: Oxygen alkaline dental's cleaners from tooth plaque, food debris, stains of blood and pus: A narrative review of the history of inventions. Journal of International Society of Preventive \& Community Dentistry. 2019; 9 (5): 427-433. 10.4103/jispcd.JISPCD_296_19.

[12] Urakov A. - Urakova N. - Chernova L.: Possibility of dissolution and removal of thick pus due to the physical-chemical characteristics of the medicines. Journal of Materials Science and Engineering B. 2013;3(11):714 - 720. https://doi.org/10.17265/2161-6221/2013.11.005.

[13] Urakov A. L. - Urakova N. A. - Alies M. Yu. - Nikityuk D. B. - Gurevich K. G. - Lovtsova L. V. - Kasatkin A. A. - Reshetnikov A. P.: Physicochemical activity of solutions as an integral part of the mechanism of local action of drugs. Pharmacy. 2019; 68 (6): 43-49. https://doi.org/10/29296/25419218-2019-06-08

[14] Urakov A. L.: The change of physical-chemical factors of the local interaction with the human body as the basis for the creation of materials with new properties. Epitöanyag - Journal of Silicate Based and Composite Materials. 2015;67(1): 2-6. http://dx.doi.org/10.14382/epitoanyag-jsbcm.2015.1.

[15] Shirato M. - Nakamura K. - Kanno T. - Lingström P. - Niwano Y. Örtengren U.: Time-kill kinetic analysis of antimicrobial chemotherapy based on hydrogen peroxide photolysis against Streptococcus mutans biofilm. Journal of Photochemistry and Photobiology B: Biology, 2017; 173:434-440. https://doi.org/10.1016/j.jphotobiol.2017.06.023.

[16] Urakov A. - Urakova N. - Reshetnikov A. - Kopylov M. - Chernova L.: Solvents of pus-medicines with physical-chemical aggressive action. IOP Conf. Series: Journal of Physics: Conf. Series. 2017;790. - 012033. https://iopscience.iop.org/article/10.1088/1742-6596/790/1/012033/pdf. 
[17] Stool Color, Changes in Color, Texture, and Form. Available from: https: //www.medicinenet.com/stool_color_changes/article.htm. [Last accessed on 2010 Feb 5].

[18] Urakov A. L. - Urakova N. A. - Gadelshina A. A.: New medicines: the bleachers of bruises, blue nails, hematomas, blood stains and bloody crusts. Australasian Medical Journal. 2017. V.10, N 11. P. 942 - 943 http://amj.net.au/index.php/AMJ/article/viewFile/3181/1606.

[19] Huang R. - Li M. - Gregory R.L.: Bacterial interactions in dental biofilm. Virulence. 2011; 2(5): 435-444. https://doi.org/10.4161/viru.2.5.16140.

[20] The Chemicals Responsible for the Color of Urine and Feces. Available from: https://www.thoughtco.com/why-is-urine-yellow-feces-brown-606813. [Last accessed on 2019 Jul 8]

[21] How people used to wash: The fascinating history of laundry. Available from: https://thescrubba.com/blogs/news/how-people-used-to-washthe-fascinating-history-of-laundry. [Last accessed on 2019 Oct 30]

[22] Callewaert C. - Nevel S.V. - Kerckhof F-M. - Granitsiotis M.S. - Boon N.: Bacterial exchange in household washing machines. Front Microbiol. 2015; 6: 1381. https:// 10.3389/fmicb.2015.01381.

[23] Industrial Dyes: Chemistry, Properties, Applications. Edit. K. Hunger. Third, Completely Revised Edition. 2003 WILEY-VCH Verlag GmbH \& Co. KGaA, Weinheim. 2003.

http://doi.org/10.1.1.674.8611\&rep=rep1\&type=pdf.

[24] Marzec A.: The effect of dyes, pigments and ionic liquids on the properties of elastomer composites. Polymers. Université Claude Bernard - Lyon I, 2014. English. https://tel.archives-ouvertes.fr/tel-01166530/document. [Last accessed on 2019 Nov 19].

[25] Bleaches. Encyclopedia.com. Available from: https://www.encyclopedia. com/science/news-wires-white-papers-and-books/bleaches. [Last accessed on 2019 Nov 19].

[26] Use of hydrogen peroxide in finfish aquaculture. Available from: https:/thefishsite.com/articles/use-of-hydrogen-peroxide-in-finfishaquaculture.pdf. [Last accessed on 2019 Jan 30].

[27] Italy Is Bleaching Old Seafood to Make It Look Fresh. Available from: https://www.vice.com/en_us/article/gvkmgq/italy-is-bleaching-oldseafood-to-make-it-look-fresh.pdf. [Last accessed on 2019 Aug 14]
[28] Albright RK - White RP.: Red blood cell susceptibility to hydrogen peroxide (H2O2) lysis in chronic hemodialysis patients. Clin Exp Dial Apheresis. 1982; 6(4):223-228. https://doi.org/10.3109/08860228209049855.

[29] Urakov A, - Urakova N.: Rheology and physical-chemical characteristics of the solutions of the medicines. Journal of Physics: Conference Series. 2015; 602: 012043. https://doi.org/10.1088/1742-6596/602/1/012043.

[30] Molenda MA - Sroa N. - Campbell SM. - Bechtel MA. - MD, Opremcak EM.: Peroxide as a novel treatment for ecchymoses. J Clin Aesthet Dermatol. 2010; 3(11): 36-38. Available from: https://www.ncbi.nlm.nih. gov/pmc/articles/PMC2989814/. [Last accessed on 2019 Nov 19].

[31] Lee H.H.B. - Park A-H. - Oloman C.: Stability of hydrogen peroxide in sodium carbonate solutions. Tappi Journal Peer Reviewed Paper. 2000:1-9. Available from: https://docplayer.net/21105316-2000-tappijournal-peer-reviewed-paper-stability-of-hydrogen-peroxide-in-sodiumcarbonate-solutions.html. [Last accessed on 2019 Nov 19].

[32] Hydrogen peroxide: practical, environmentally friendly and antibacterial (2007-2008) Did you know there were so many uses for hydrogen peroxide? Available from: http://www.using-hydrogen-peroxide.com/ [Last accessed on 2019 Jan 30].

[33] Albright RK - White RP.: Red blood cell susceptibility to hydrogen peroxide (H2O2) lysis in chronic hemodialysis patients. Clin Exp Dial Apheresis. 1982;6(4):223-228. https://doi.org/10.3109/08860228209049855.

[34] U. S. Government Printing Office via GPO Access. Code of Federal Regulations, Title 21, Volume 6. Available from: 21CFR582.1366 FDA. [Last accessed on 20191 Jan 30].

\section{Ref.:}

Urakov, Aleksandr: Creation of "necessary" mixtures of baking soda, hydrogen peroxide and warm water as a strategy for modernization bleaching cleaners of ceramic

Építöanyag - Journal of Silicate Based and Composite Materials, Vol. 72, No. 1 (2020), 30-35. p.

https://doi.org/10.14382/epitoanyag-jsbcm.2020.6

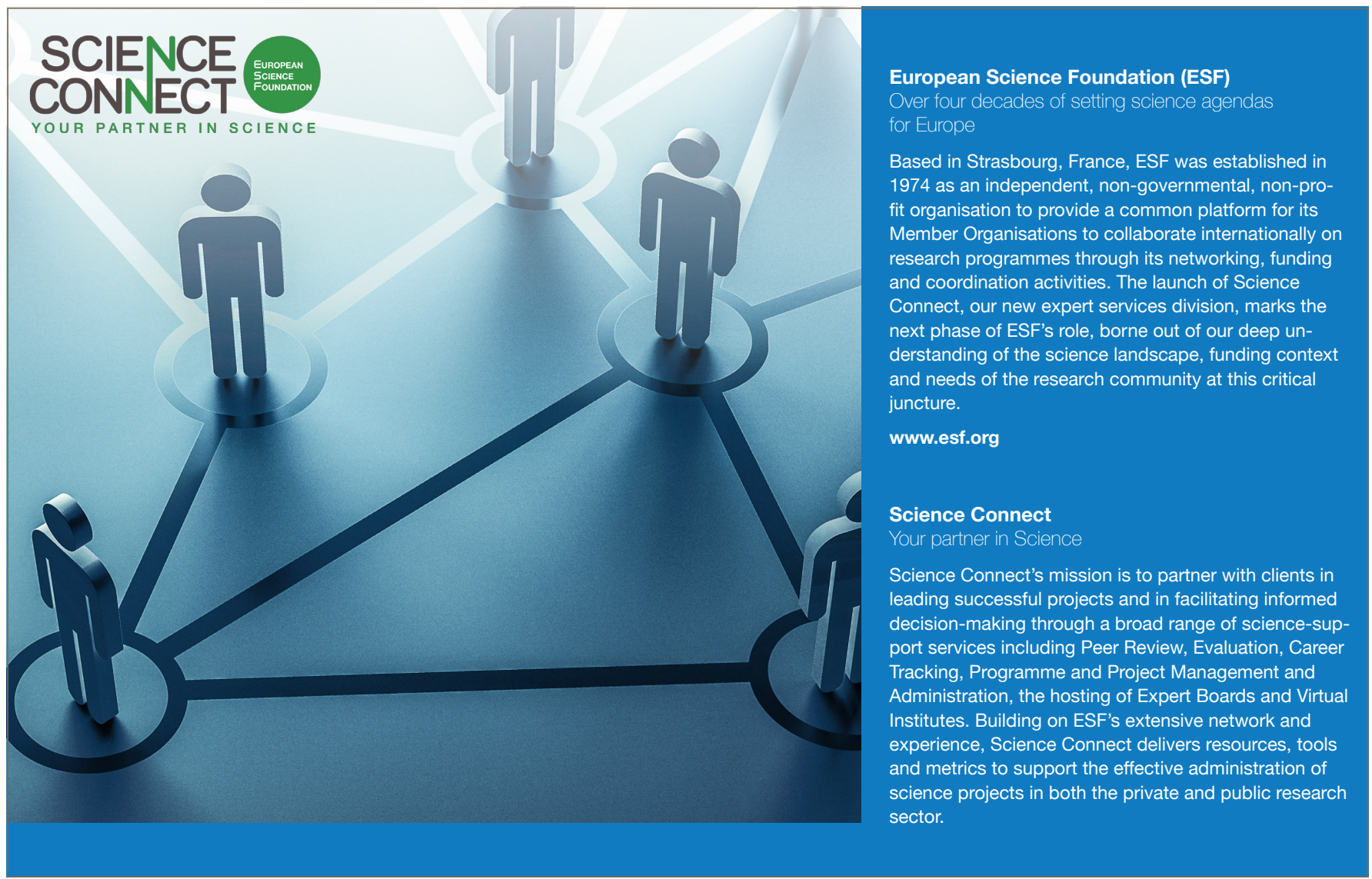

